\title{
Bone morphogenetic protein 9 regulates tumor growth of osteosarcoma cells through the Wnt/ $\beta$-catenin pathway
}

\author{
ZILAN LV ${ }^{1}$, CHUAN WANG ${ }^{2}$, TAIXIAN YUAN ${ }^{1}$, YUEHONG LIU ${ }^{3}$, TAO SONG $^{1}$, YUELIANG LIU ${ }^{1}$,

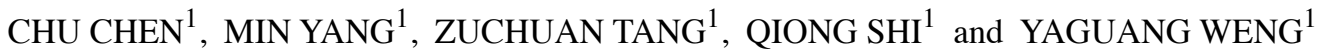 \\ ${ }^{1}$ Key Laboratory of Diagnostic Medicine Designated by the Chinese Ministry of Education, Chongqing Medical University, \\ Chongqing 400016; ${ }^{2}$ Department of Gastroenterology, The Third People's Hospital of Chongqing, Chongqing 400014; \\ ${ }^{3}$ Department of Clinical Laboratory, The Fourth Hospital of Xi'an, Xi'an, Shaanxi 710004, P.R. China
}

Received October 16, 2013; Accepted November 29, 2013

DOI: $10.3892 /$ or.2013.2931

\begin{abstract}
Bone morphogenetic protein 9 (BMP9) is a member of the transforming growth factor- $\beta$ (TGF- $\beta$ ) family, which has been shown to regulate the progression of several tumors. Recent studies indicated that BMP9 affects osteosarcoma (OS) processes, but its specific roles and molecular mechanisms have yet to be fully elucidated. The human OS cell lines 143B and MG63 were used for the present study. We found that BMP9 overexpression suppressed the growth of OS cells, whereas inhibition of BMP9 reversed this effect. Our results also showed that BMP9 overexpression induced G0/G1 phase arrest and apoptosis in OS cells. We further investigated the possible molecular mechanisms mediating the biological role of BMP9. We observed that BMP9 overexpression reduced $\beta$-catenin mRNA and protein levels, and also downregulated its downstream proteins c-Myc and osteoprotegerin (OPG) and inhibited the phosphorylation levels of GSK-3 $\beta$ (Ser 9) in OS cells, whereas inhibition of BMP9 reversed these effects. Moreover, the suppressive effects of BMP9 overexpression on OS cells was reversed by exogenous $\beta$-catenin expression, but augmented by $\beta$-catenin silencing. In conclusion, our results revealed that BMP9 can regulate tumor growth of OS cells through the Wnt/ $\beta$-catenin pathway. Therefore, BMP9 may be a new therapeutic target in OS.
\end{abstract}

\section{Introduction}

Osteosarcoma (OS) is the most common primary malignant tumor arising from bone in children and young adults (1).

Correspondence to: Professor Yaguang Weng or Dr Qiong Shi, Key Laboratory of Diagnostic Medicine Designated by The Chinese Ministry of Education, Chongqing Medical University, 1 Yixueyuan Road, Chongqing 400016, P.R. China

E-mail: yaguangweng@126.com

E-mail: anniesq8718@aliyun.com

Key words: bone morphogenetic protein 9, osteosarcoma, $\beta$-catenin, c-myc, osteoprotegerin
Despite aggressive chemotherapeutic treatment strategies, the survival of these patients has limited improvement. The prognosis is very poor, and the 5-year mortality rate for OS patients remains at $40 \%$ (2).

The canonical Wnt signaling pathway $\beta$-catenin is considered the key component of this pathway, which plays important roles during embryonic development and oncogenesis $(3,4)$. It was reported that $\beta$-catenin has a key role in the Wnt signaling pathway, which is important in cell growth, mobility, differentiation and tumor formation (5). Previous studies have demonstrated that cytoplasmic and nuclear $\beta$-catenin protein is frequently elevated in human OS (6), and a high level of intracytoplasmic and/or nuclear expression of $\beta$-catenin in OS cells was associated with pulmonary metastasis (7). In the lack of Wnt ligands, cytoplasmic $\beta$-catenin protein is phosphorylated through a complex containing GSK3 $3 / \mathrm{APC} /$ Axin followed by degradation. In tumor cells, $\beta$-catenin may aberrantly accumulate in the cytosol and further translocates into the nucleus where it interacts with T-cell factor/lymphoid enhancing factor $(\mathrm{TCF} / \mathrm{LEF})$ that regulate expression of several downstream target genes including c-myc, cyclin D1, MMP7 (encoding matrix metalloproteinase 7) and osteoprotegerin (OPG) (8-10), which play important roles in tumorigenesis and metastasis.

Bone morphogenetic proteins (BMPs) belong to the transforming growth factor- $\beta$ (TGF- $\beta$ ) superfamily. BMPs regulate a wide range of physiologic events, including cell proliferation, differentiation, apoptosis, migration and invasion $(11,12)$. BMP9 is probably the most osteogenic differentiation potent inducer; it was reported that autocrine BMP9 promotes ovarian cancer and human hepatocellular carcinoma cell proliferation, and BMP9 overexpression prevents prostate and breast cancer cell growth (13-16). Although the role of BMP9 in several types of cancer has been documented, its roles in OS and molecular mechanisms have yet to be well investigated. Thus, in the present study, we investigated the role of BMP9 on the growth of the human OS 143B and MG63 cells following both overexpression and knockout of BMP9. To increase our understanding of the molecular mechanisms underlying BMP9 in the development of OS, we investigated the underlying involvement of $\beta$-catenin signaling in human OS. 


\section{Materials and methods}

Materials. Dulbecco's modified Eagle's medium-high glucose (DMEM-HG) and fetal bovine serum (FBS) were purchased from HyClone. The human embryonic kidney cell line HEK293 and the human OS cell lines 143B and MG63 were obtained from the American Type Culture Collection (ATCC, Manassas, VA, USA). Recombinant adenovirus expressing green fluorescent protein (AdGFP), red fluorescent protein (AdRFP), BMP9 (AdBMP9), $\beta$-catenin (Ad $\beta$-catenin) were donated by Professor T.C. He, Chicago University, USA. Recombinant adenoviruses expressing siRNA targeted $\beta$-catenin (Adsi $\beta$-catenin), BMP9 (AdsiBMP9) with RFP were generated in our laboratory. TRIzol reagent was purchased from Invitrogen. RT-PCR reagents were purchased from Takara Biotech (Liaoning, China). Anti-GSK-3 $\beta$, anti-p-GSK-3 $\beta$, anti- $\beta$-catenin, anti- $\beta$-actin, anti-C-myc, anti-OPG antibodies were purchased from Santa Cruz Biotechnology, Inc. (Santa Cruz, CA, USA). Secondary antibody reagents were obtained from Zhongshan Golden Bridge, Beijing, China. Western blot detection reagents were purchased from Beyotime Institute of Biotechnology (Jiangsu, China). BeyoECL was purchased from Millipore.

Cell culture, preparation of BMP9 conditioned medium and adenovirus infection. The HEK293 and human OS cell lines 143B and MG63 were maintained in DMEM-HG; HCT116 cells were maintained in MEM-HG supplemented with $10 \% \mathrm{FBS}$ and $100 \mathrm{U} / \mathrm{ml}$ of penicillin $\mathrm{G} /$ streptomycin at $37^{\circ} \mathrm{C}$ in 5\% $\mathrm{CO}_{2}$. HEK293 cells were used for adenovirus amplification. Log-phase HCT116 cells were infected with AdBMP9. After infection for 4-6 h, the culture medium was changed to serum-free DMEM. After further culture for $24 \mathrm{~h}$, supernatants were collected and used immediately. OS cells were treated with AdBMP9, AdsiBMP9, Ad $\beta$-catenin, Adsi $\beta$-catenin or the control adenovirus AdGFP, AdRFP. After infecting for 8-12 h, the medium was replaced with serum-free or low serum DMEM, Ad $\beta$-catenin, Adsi $\beta$-catenin infected cells replaced with BMP9 conditional medium.

Cell proliferation assay. OS cells were seeded in 96-well culture plates. On the following day, the cells were treated with AdBMP9, AdsiBMP9 or Ad $\beta$-catenin, Adsi $\beta$-catenin with BMP9 conditioned medium. At the indicated time, the supernatant was removed and $20 \mu \mathrm{l}$ of the MTT reagent $(5 \mathrm{mg} / \mathrm{ml})$ was added. The mixture was then incubated for $4 \mathrm{~h}$, the MTT solution was removed and formazan was dissolved in DMSO, and then absorbance was measured at $490 \mathrm{~nm}$ using a Sunrise remote microplate reader.

Cell cycle and apoptosis analysis. Log-phase cells from each group were harvested by centrifugation. After washing twice with ice-cold PBS and resuspending, cell cycle distribution and apoptosis were analyzed by a FACSVantage SE flow cytometer (Becton-Dickinson, USA). Each experiment was performed thrice.

RNA extraction and RT-PCR analysis. Total RNA was extracted from OS cells using TRIzol reagent, according to the manufacturer's instructions. First-strand DNA was synthesized using the Reverse Transcriptase M-MLV (RNase $\mathrm{H}^{-}$) kit with random hexamer primers. PCR products were separated by electrophoresis on a $2 \%$ agarose gels. The primers were: $\beta$-catenin (forward, 5'-CTGCAGGGGTCCTCTGTG-3' and reverse, 5'-TGCATATGTCGCCACACC-3'; 125 bp), C-myc (forward, 5'-TACCCTCTCAACGACAGCAG-3' and reverse, 5'-TCTTGACATTCTCCTCGGTG-3'; 478 bp), OPG (forward, 5'-AGTGGGAGCAGAAGACAT-3' and reverse, 5'-TGGA CCTGGTTACCTATC-3'; 264 bp), GAPDH (forward, 5'-CAG CGACACCCACTCCTC-3' and reverse, 5'-TGAGGTCCA CCACCCTGT-3'; 122 bp).

Western blot analysis. Briefly, OS cells were lysed with RIPA buffer, then centrifuged at $13,000 \mathrm{xg}$ for $5 \mathrm{~min}$ at $4^{\circ} \mathrm{C}$ and supernatants were collected. The protein concentration was determined by the BCA assay. Proteins were denatured, separated on a $10 \%$ SDS-PAGE and transferred to a PVDF membrane, after blocking with BSA for $2 \mathrm{~h}$, probed with primary antibody incubation, followed by a secondary $\operatorname{IgG}$ antibody incubation for $1 \mathrm{~h}$. The proteins were detected using SuperSignal West Pico Chemiluminescent Substrate kit.

Statistical analysis. Data are expressed as the means \pm SD. Statistical analysis was performed using GraphPad Prism 5. $\mathrm{p}<0.05$ was considered to indicate a statistically significant difference.

\section{Results}

In vitro cell viability depends on BMP9 expression. To investigate the effects of BMP9 on cell growth, OS cells were treated with AdBMP9 and AdsiBMP9 for 24, 48 and $72 \mathrm{~h}$ and cell viability was examined by MTT assay. As shown in Fig. 1, the cell viability of OS cells treated with AdBMP9 was significantly inhibited at $24 \mathrm{~h}$ and tended to be more significant at 48 and $72 \mathrm{~h}$, whereas the cell viability of OS cells treated with AdsiBMP9 was significantly promoted only at $48 \mathrm{~h}$. These results suggest that BMP9 overexpression inhibits the growth of OS cells.

BMP9 overexpression induces G1 cell cycle arrest in OS cells. To determine whether the growth inhibition observed in OS cells is associated with induction of cell cycle arrest, we next examined the effects of BMP9 overexpression on OS cell cycle distribution by flow cytometry. The data showed that BMP9 overexpression decreased the percentage of $143 \mathrm{~B}$ and MG63 cells in the S phase from 59.32 \pm 5.16 to $39.07 \pm 4.16 \%(p<0.05)$ and $42.75 \pm 4.69$ to $9.41 \pm 3.82 \%$ $(\mathrm{p}<0.05)$ compared to the AdGFP group, and increased the percentage of 143B and MG63 cells at the G1 phase of the cell cycle from $31.14 \pm 3.29$ to $47.83 \pm 4.66 \%(\mathrm{p}<0.05)$ and $43.36 \pm 3.11$ to $82.65 \pm 3.68 \%(\mathrm{p}<0.05)$ compared to the AdGFP group, respectively (Fig. 2).

BMP9 overexpression induces apoptosis in $143 B$ cells. We then examined whether BMP9 overexpression induces apoptosis in OS cells by flow cytometry. Fig. 3A and C shows that the apoptosis rate of $143 \mathrm{~B}$ cells was significantly increased from $10.23 \pm 2.61$ to $19.91 \pm 2.29 \%(\mathrm{p}<0.05)$ compared to AdGFP groups after BMP9 treatment for $48 \mathrm{~h}$, whereas the 
A

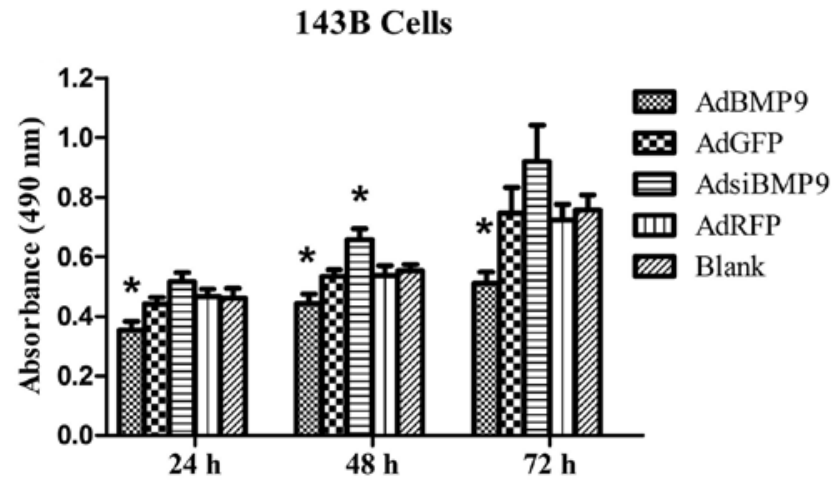

B

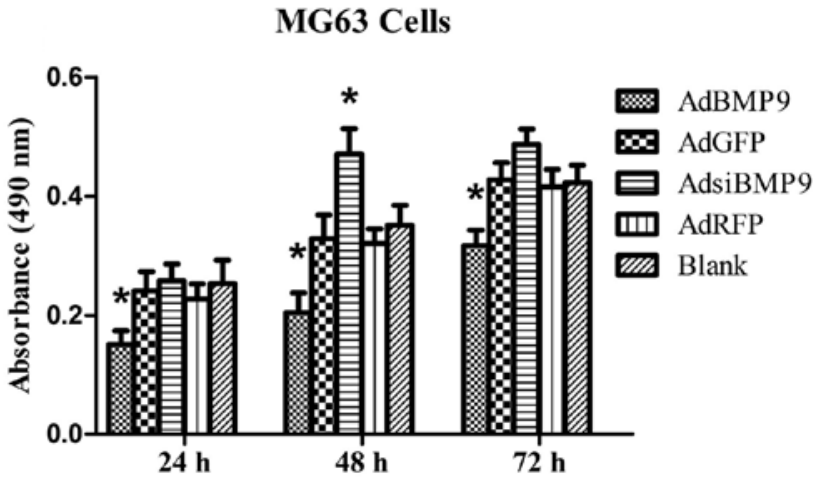

Figure 1. In vitro cell viability depends on BMP9 expression. (A) 143B and (B) MG63 cells were infected with AdBMP9 or AdsiBMP9 for 24,48 and 72 h. At the end of the indicated time, cell viability was determined by MTT assays. " $\mathrm{p}<0.05$ vs. AdGFP/AdRFP and blank.

A
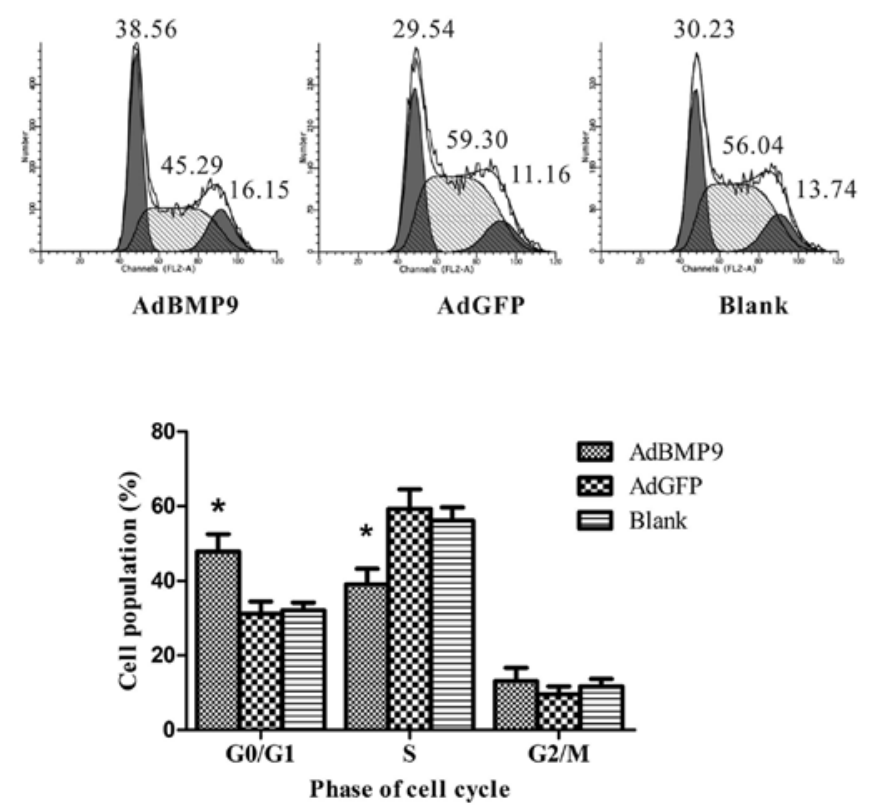

B
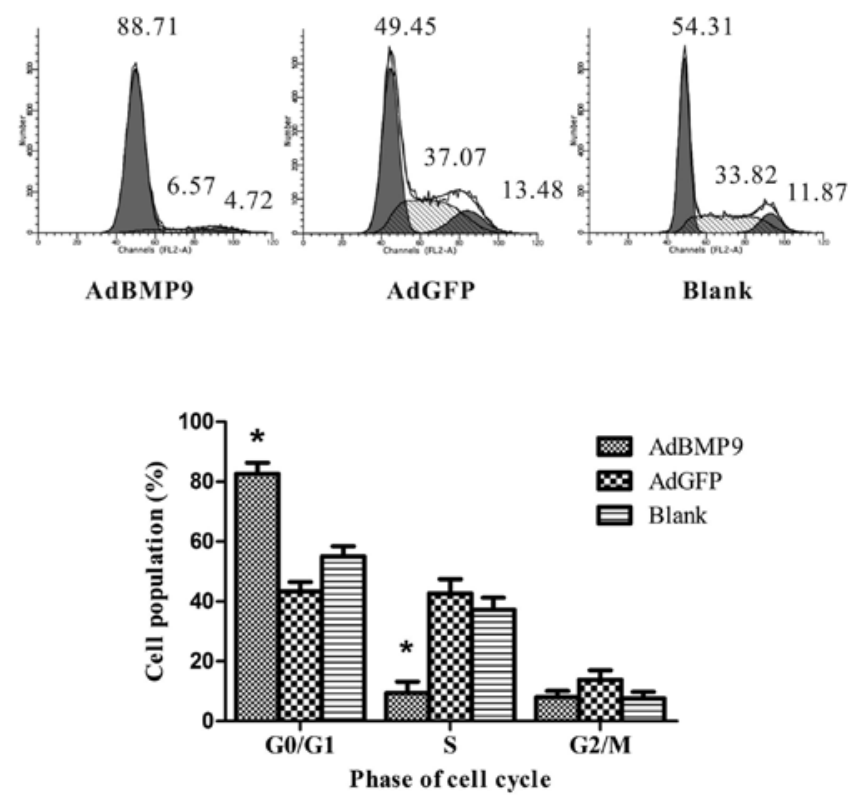

Figure 2. BMP9 overexpression induces G1 cell cycle arrest in OS cells. (A) 143B and (B) MG63 cells were infected with AdBMP9 for $48 \mathrm{~h}$. Cell cycle distribution was analyzed by flow cytometry. The data are expressed as the means $\pm \mathrm{SD}(\mathrm{n}=3)$. The assay was performed in triplicate. ${ }^{*} \mathrm{p}<0.05 \mathrm{vs}$. AdGFP and blank.

apoptosis rate of MG63 cells was not significantly higher than that of the AdGFP groups after BMP9 treatment for $48 \mathrm{~h}$ (Fig. 3B and D).

Expression of $\beta$-catenin and its downstream target genes depend on BMP9 expression. To determine $\beta$-catenin and further understand the regulation of the several target genes by $\beta$-catenin, we detected $\beta$-catenin and its downstream target genes c-myc and OPG using RT-PCR and western blot analysis. As shown in Fig. 4, our results demonstrated that levels of $\beta$-catenin and its target genes c-myc and OPG were significantly reduced at both the mRNA and protein levels in OS cells after infection with AdBMP9 for $24 \mathrm{~h}$, whereas they reverted after infection with AdsiBMP9.
GSK-3 $\beta$ activity depends on BMP9 expression. To evaluate the effects of BMP9 on phosphorylated GSK-3 $\beta^{\text {Ser9 }}$, the total GSK- $3 \beta$ and phosphorylated GSK- $3 \beta^{\text {Ser9 }}$ were determined by western blotting. Fig. 5 shows that BMP 9 overexpression significantly reduced GSK- $3 \beta^{\text {Ser9 }}$ phosphorylation in OS cells and the suppressive effect was reverted by inhibition of BMP9. This data indicates that BMP9 might downregulate $\beta$-catenin by activating GSK-3 $\beta$.

BMP9 inhibits the growth of OS cells through the Wnt/ $\beta$ catenin signaling pathways. To determine whether the effect of BMP9 on OS cells is associated with Wnt/ $\beta$-catenin signaling, cell viability was determined by MTT assays. The efficiency of $\operatorname{Ad} \beta$-catenin and Adsi $\beta$-catenin was previously confirmed 
A

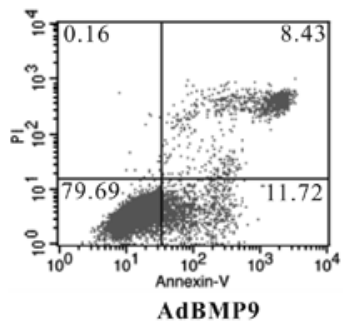

B

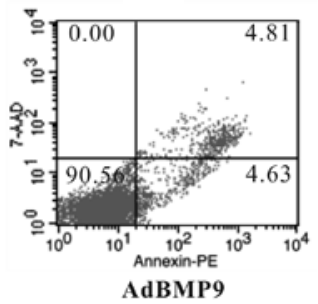

143B Cells

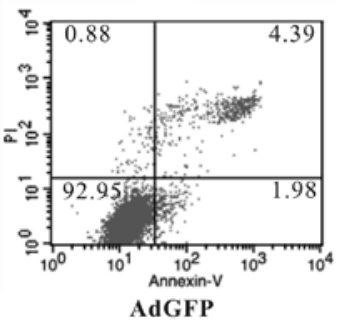

MG63 Cells

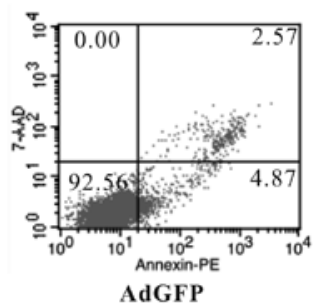

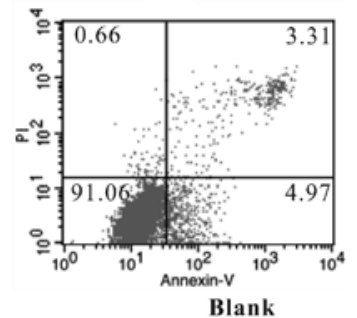

Blank

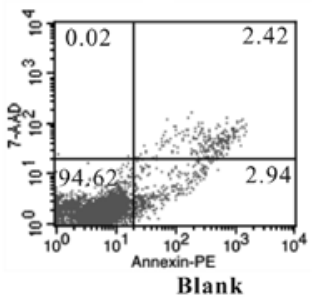

C

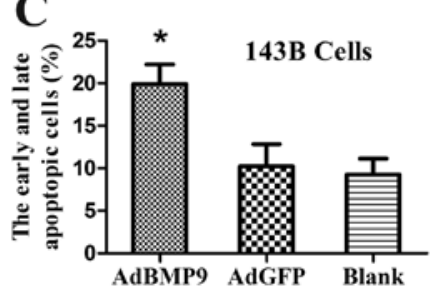

D

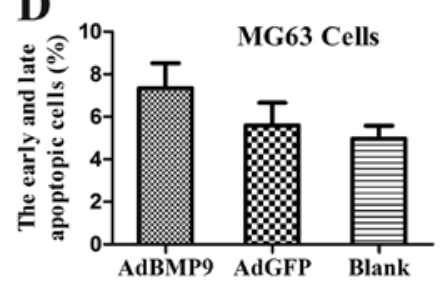

Figure 3. BMP9 overexpression induces apoptosis in 143B cells. (A) 143B and (B) MG63 cells were infected with AdBMP9 for 48 h, and were then analyzed for apoptosis by flow cytometry. The percentage of apoptotic cells in (C) 143B and (D) MG63 cells for each group. Values are the means \pm SD ( $n=3$ ). ${ }^{*} \mathrm{p}<0.05$ vs. AdGFP and blank.

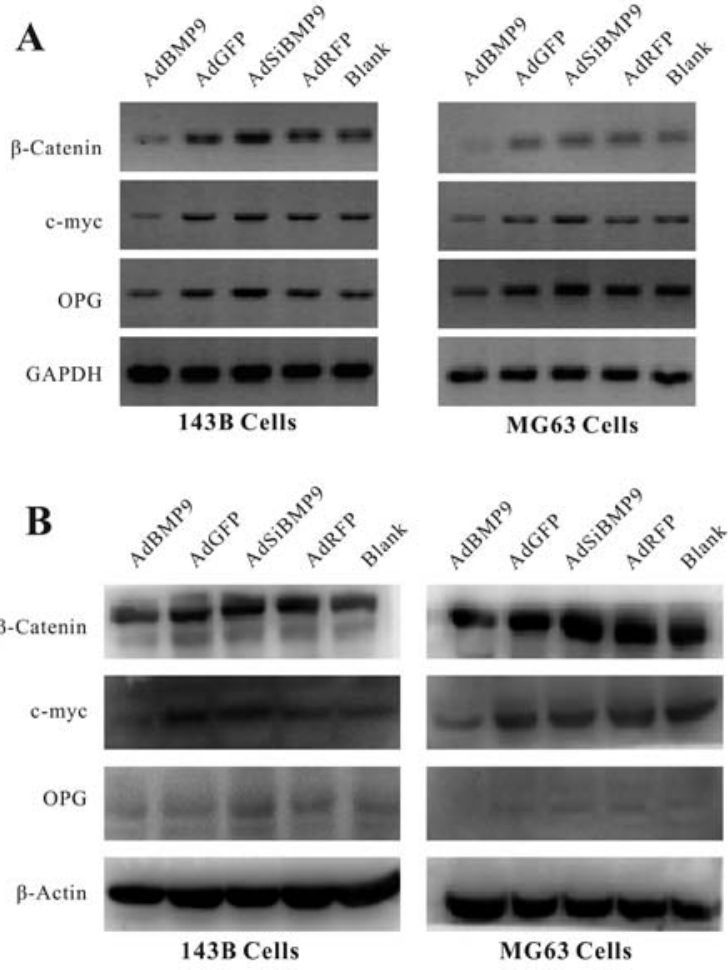

Figure 4. Expression of $\beta$-catenin and its downstream target genes depends on BMP9 expression. 143B and MG63 cells were infected with AdBMP9 or AdsiBMP9 for $24 \mathrm{~h}$. (A) The mRNA levels of $\beta$-catenin, c-myc and OPG were examined by RT-PCR; (B) the protein levels of $\beta$-catenin, c-myc and OPG were examined by western blot assay.
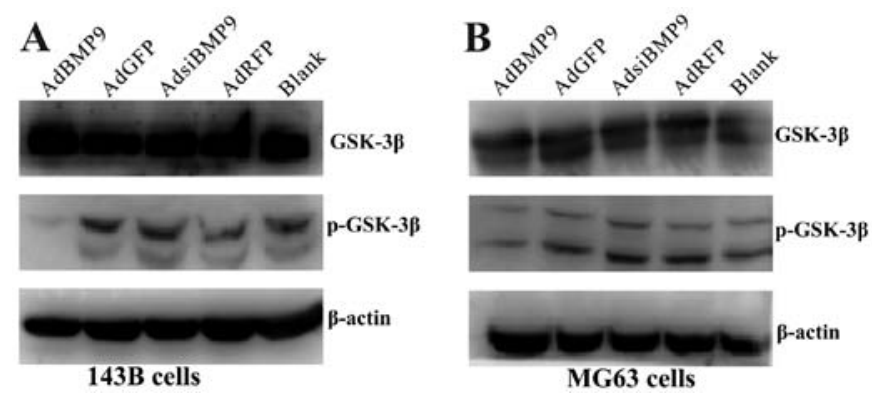

Figure 5. GSK-3 $\beta$ activity depends on BMP9 expression. (A) 143B and (B) MG63 cells were infected with AdBMP9 or AdsiBMP9 for $24 \mathrm{~h}$. Total GSK- $3 \beta$ and p-GSK-3 $\beta$ protein levels were examined by western blot assay.

by our group (17); we observed that the proliferation potency of exogenous $\beta$-catenin expression of 143B cells treated with BMP9 was restored compared with AdGFP infection treated with BMP9, whereas knockout of $\beta$-catenin of 143B cells treated with BMP9 was enhanced compared with AdRFP infection treated with BMP9 (Fig. 6A). Similarly, $\beta$-catenin target genes c-myc and OPG expression were restored after exogenous $\beta$-catenin expression of 143B cells treated with BMP9, whereas they were reduced after knockout of $\beta$-catenin expression of 143B cells treated with BMP9, compared with AdGFP or AdRFP infection treated with BMP9, respectively (Fig. 6B). The data showed that BMP9 overexpression inhibits cell viability of 143B cells possibly through the Wnt/ß-catenin pathway. 

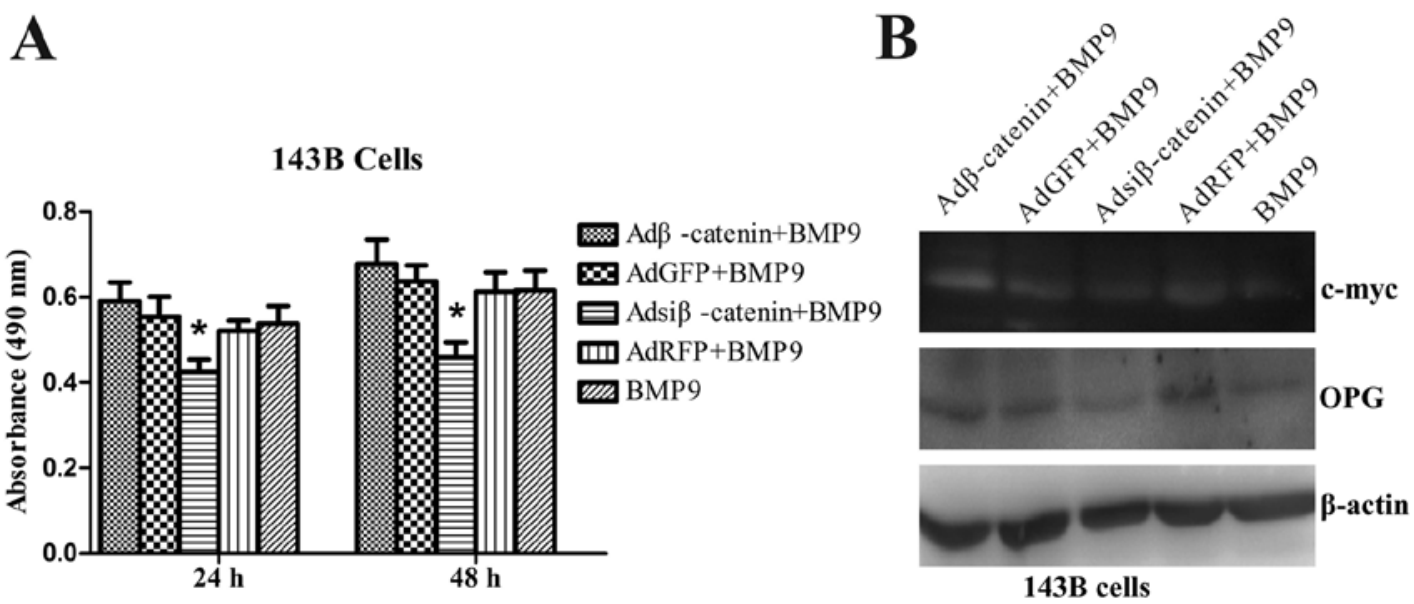

Figure 6. BMP9 inhibits the growth of OS cells through the wnt/ $\beta$-catenin signaling pathways. (A) $143 \mathrm{~B}$ cells were infected with Ad $\beta$-catenin and Adsi $\beta$-catenin with BMP9 conditioned medium for 24 and $48 \mathrm{~h}$. At the end of the indicated time, cell viability was determined by MTT assays. "p<0.05 vs. control group. (B) 143B cells were infected with Ad $\beta$-catenin and Adsi $\beta$-catenin with BMP 9 conditioned medium for $24 \mathrm{~h}$; c-myc and OPG protein levels were examined by western blot assay.

\section{Discussion}

BMPs are a member of the TGF- $\beta$ superfamily and were originally identified to play important roles in regulating bone and cartilage formation (18). More recently, BMPs were found to express various human cancer cells including prostate, gastric, ovarian, pancreatic, colon carcinoma, breast cancer, OS and multiple myeloma $(11,19)$. Recent studies suggest that BMP2 is involved in OS progression (20). BMP9 was reported to probably be the most potent inducer (21) and we previously showed it is expressed in OS cell lines 143B and MG63 and its overexpression inhibits OS cell migration and invasion (22); however, the effect of BMP9 on OS has not yet been fully elucidated.

In the present study, we observed that BMP9 overexpression had a significant inhibitory effect on OS cell viability in a timedependent manner, whereas BMP9 silencing induced opposite effects. A possible explanation for the growth inhibition of BMP9 on OS cells is either cell cycle arrest or apoptosis increase. Our results indicated that BMP9 induced cell cycle arrest in the G1 phase in the two OS cell lines, but only induced cell apoptosis of 143B cells. This may explain the different metastatic properties of the two OS cell lines. This result is consistent with previous studies that have shown an inhibitory effect of BMP9 overexpression on cancer cell growth including prostate and breast cancer $(15,16)$. However, our findings on OS cell lines in vitro differ from previous observations that BMP9 induces proliferation of several cells, including ovarian cancer and human hepatocellular carcinoma $(13,14)$. The inconsistency of the effects of BMP9 on cancer cells may result from dosage, type of cell or/and microenvironment differences.

Previous studies have demonstrated that deregulation of $\beta$-catenin signaling is heavily implicated in the development and progression of various types of cancer including colorectal, melanoma, gastric, hepatic breast cancer and OS $(23,24)$. $\beta$-catenin signaling is commonly deregulated in human OS, which is implicated in the pathogenesis of OS $(6,7)$. In addition, restoration of BMP signaling decreased $\beta$-catenin expression and inhibited Wnt signaling in colon cancer (25). To further investigate the mechanisms of BMP9 on the regu- lation of cell viability, the level of $\beta$-catenin was determined by RT-PCR and western blot assay. Our results revealed that BMP9 overexpression downregulated $\beta$-catenin expression, whereas BMP9 silencing induced opposite effects.

BMPs can regulate OPG expression and bone-derived OPG was found to protect several cancer cells from TRAILinduced apoptosis including breast cancer, prostate cancer and multiple myeloma cells (10,26-28). Moreover, OPG expression was found to be negatively correlated with increasing breast tumor grade (29). Our data showed that BMP9 overexpression decreased expression of c-myc and OPG, whereas knockout of BMP9 reverted these effects. We also showed that exogenous $\beta$-catenin expression can neutralize these effects of BMP9, whereas knockout of $\beta$-catenin can enhance these effects of BMP9. Collectively, we hypothesized that BMP9 inhibits the growth of OS cells possibly through the Wnt/ $\beta$-catenin pathway.

GSK-3 $\beta$ phosphorylates $\beta$-catenin, followed by rapid degradation of $\beta$-catenin via the ubiquitin-proteasome pathway, which regulates processes including differentiation, growth, motility and apoptosis $(8,30,31)$. Our results showed that BMP9 overexpression downregulated p-GSK- $3 \beta^{\text {Ser9 }}$ protein levels, whereas BMP9 silencing induced opposite effects. These findings are compatible with the hypothesis that the activated GSK-3 $\beta$ resulted in G1 cell-cycle arrest and apoptosis. In contrast, inactivation of GSK-3 $\beta$ leads to cell-cycle progression and resistance to apoptosis in human lung cancer cells (32). However, whether GSK-3 $\beta$ activation is critical for BMP9inhibited growth of OS cells requires further investigation.

In conclusion, our results suggest that BMP9 overexpression inhibits OS cell growth, induces cell G1 phase arrest and apoptosis, and these suppressive effects may be mediated by the Wnt/ $\beta$-catenin pathway. We also demonstrated that BMP9 overexpression increased GSK-3 $\beta$ activity by decreasing its phosphorylation on ser 9 residue GSK-3 $\beta^{\text {Ser9; }}$ therefore, we further propose that inhibiting Wnt/ $\beta$-catenin may be through increasing GSK-3 $\beta$ activity. Our results indicate that BMP9 overexpression may prove to be a valuable tool for inhibition of cancer growth. Further studies to elucidate the relationship between BMP signaling and Wnt signaling are required. 


\section{Acknowledgements}

We are grateful to Dr T.C. He of The University of Chicago Medical Center for providing the adenoviruses. This study was supported by National Ministry of Education Foundation of China (20115503110009), grant 31200971 from the National Natural Science Foundation of China (NSFC31200971), by Program of the Ministry of Science and Technology of Yu-zhong District, CQ (20130136) and by the Science and Technology Research Project of Chongqing Education Commission (KJ120327).

\section{References}

1. Young JL Jr and Miller RW: Incidence of malignant tumors in U.S. children. J Pediatr 86: 254-258, 1975.

2. Fagioli F, Biasin E, Mereuta OM, et al: Poor prognosis osteosarcoma: new therapeutic approach. Bone Marrow Transpl 41: S131-S134, 2008.

3. Barker N: The canonical Wnt/beta-catenin signalling pathway. Methods Mol Biol 468: 5-15, 2008.

4. Clevers $\mathrm{H}$ : Wnt/beta-catenin signaling in development and disease. Cell 127: 469-480, 2006.

5. Behrens J: Control of beta-catenin signaling in tumor development. Ann NY Acad Sci 910: 21-35, 2000.

6. Haydon RC, Deyrup A, Ishikawa A, et al: Cytoplasmic and/or nuclear accumulations of the beta-catenin protein is a frequent event in human osteosarcoma. Int J Cancer 102: 338-342, 2002.

7. Iwaya K, Ogawa H, Kuroda M, Izumi M, Ishida T and Mukai K Cytoplasmic and/or nuclear staining of beta-catenin is associated with lung metastasis. Clin Exp Metastasis 20: 525-529, 2003

8. MacDonald BT, Tamai $\mathrm{K}$ and $\mathrm{He} \mathrm{X}$ : Wnt/beta-catenin signaling: components, mechanisms, and diseases. Dev Cell 17: 9-26, 2009

9. McQueen P, Ghaffar S, Guo Y, Rubin EM, Zi X and Hoang BH: The Wnt signaling pathway: implications for therapy in osteosarcoma. Expert Rev Anticancer Ther 11: 1223-1232, 2011.

10. Sato MM, Nakashima A, Nashimoto M, Yawaka $Y$ and Tamura M: Bone morphogenetic protein-2 enhances Wnt/betacatenin signaling-induced osteoprotegerin expression. Genes Cells 14: 141-153, 2009.

11. Singh A and Morris RJ: The Yin and Yang of bone morphogenetic proteins in cancer. Cytokine Growth Factor Rev 21: 299-313, 2010.

12. Kim M and Choe S: BMPs and their clinical potentials. BMB Rep 44: 619-634, 2011.

13. Herrera B, van Dinther M, ten Dijke P and Inman GJ: Autocrine bone morphogenetic protein-9 signals through activin receptorlike kinase-2/Smad1/Smad4 to promote ovarian cancer cell proliferation. Cancer Res 69: 9254-9262, 2009.

14. Herrera B, García-Álvaro M, Cruz S, et al: BMP9 is a proliferative and survival factor for human hepatocellular carcinoma cells. PloS One 8: e69535, 2013.
15. Ye L, Kynaston $\mathrm{H}$ and Jiang WG: Bone morphogenetic protein- 9 induces apoptosis in prostate cancer cells, the role of prostate apoptosis response-4. Mol Cancer Res 6: 1594-1606, 2008.

16. Wang K, Feng H, Ren W, et al: BMP9 inhibits the proliferation and invasiveness of breast cancer cells MDA-MB-231. J Cancer Res Clin 137: 1687-1696, 2011.

17. Liu Y, Wang W, Xu J, et al: Dihydroartemisinin inhibits tumor growth of human osteosarcoma cells by suppressing Wnt $/ \beta$ catenin signaling. Oncol Rep 30: 1723-1730, 2013.

18. Chen D, Zhao M and Mundy GR: Bone morphogenetic proteins. Growth Factors 22: 233-241, 2004.

19. Grcevic D, Kusec R, Kovacic N, et al: Bone morphogenetic proteins and receptors are over-expressed in bone-marrow cells of multiple myeloma patients and support myeloma cells by inducing ID genes. Leukemia Res 34: 742-751, 2010.

20. Wang L, Park P, Zhang H, et al: BMP-2 inhibits the tumorigenicity of cancer stem cells in human osteosarcoma OS99-1 cell line. Cancer Biol Ther 11: 457-463, 2011.

21. Kang Q, Sun MH, Cheng H, et al: Characterization of the distinct orthotopic bone-forming activity of 14 BMPs using recombinant adenovirus-mediated gene delivery. Gene Ther 11: 1312-1320, 2004.

22. Lv Z, Yang D, Li J, et al: Bone morphogenetic protein 9 overexpression reduces osteosarcoma cell migration and invasion. Mol Cells 36: 119-126, 2013.

23. Luo J, Chen J, Deng Z-L, et al: Wnt signaling and human diseases: what are the therapeutic implications? Lab Invest 87: 97-103, 2007.

24. Flores RJ, Li Y, Yu A, et al: A systems biology approach reveals common metastatic pathways in osteosarcoma. BMC Syst Biol 6: 50, 2012.

25. Freeman TJ, Smith JJ, Chen X, et al: Smad4-mediated signaling inhibits intestinal neoplasia by inhibiting expression of $\beta$-catenin. Gastroenterology 142: 562-571, 2012.

26. Neville-Webbe HL, Cross NA, Eaton CL, et al: Osteoprotegerin (OPG) produced by bone marrow stromal cells protects breast cancer cells from TRAIL-induced apoptosis. Breast Cancer Res Treat 86: 269-279, 2004.

27. Nyambo R, Cross N, Lippitt J, et al: Human bone marrow stromal cells protect prostate cancer cells from TRAIL-induced apoptosis. J Bone Miner Res 19: 1712-1721, 2004.

28. Shipman CM and Croucher PI: Osteoprotegerin is a soluble decoy receptor for tumor necrosis factor-related apoptosisinducing ligand/Apo2 ligand and can function as a paracrine survival factor for human myeloma cells. Cancer Res 63: 912-916, 2003.

29. Holen I, Cross SS, Neville-Webbe HL, et al: Osteoprotegerin (OPG) expression by breast cancer cells in vitro and breast tumours in vivo - a role in tumour cell survival? Breast Cancer Res Treat 92: 207-215, 2005.

30. Fodde R and Brabletz T: Wnt/beta-catenin signaling in cancer stemness and malignant behavior. Curr Opin Cell Biol 19: $150-158,2007$.

31. Forde JE and Dale TC: Glycogen synthase kinase 3: A key regulator of cellular fate. Cell Mol Life Sci 64: 1930-1944, 2007.

32. Li J, Xing M, Zhu M, et al: Glycogen synthase kinase 3 beta induces apoptosis in cancer cells through increase of survivin nuclear localization. Cancer Lett 272: 91-101, 2008. 